\title{
Potencial e participação das florestas na matriz energética
}

\author{
José Mauro Magalhães Ávila Paz Moreira ${ }^{1}$ \\ 'Embrapa Florestas, Estrada da Ribeira, Km 111, CP 319, CEP 83.411-000, Colombo, PR, Brasil
}

"Autor correspondente:

josemauro@cnpf.embrapa.br

Termos para indexação:

Energia renovável

Biomassa florestal

Florestas energéticas

Index terms:

Renewable energy

Forest biomass

Energetic forests

\section{Histórico do artigo:}

Recebido em 02 jun 2011

Aprovado em 26 out 2011

Publicado em 28 dez 2011

doi: $10.4336 / 2011 . p f b .31 .68 .363$
Resumo - Algumas nações têm buscado aumentar a participação de fontes renováveis na sua matriz energética, com o objetivo de reduzir as emissões de gases de efeito estufa (GEE). Avaliações do potencial da biomassa, inclusive de origem florestal, para geração de energia, tem sido o foco de vários estudos no Brasil e no mundo, concluindo que a biomassa apresenta um forte potencial para geração de energia, com vantagens para a redução da emissão de GEE, sendo de fácil acesso e disponível localmente a custos competitivos em vários países. No Brasil, a madeira para energia tem perdido participação na matriz energética, mas o seu consumo tem aumentado na última década, sendo as regiões Sul e Nordeste as principais produtoras nacionais de lenha, e a Sudeste a principal produtora de carvão vegetal. Para aumentar o potencial de geração de energia de biomassa florestal no país seria necessária a difusão de tecnologias silviculturais e de carbonização para pequenos e médios produtores, além do aumento da área plantada para atender a demanda crescente de madeira para energia no futuro próximo.

\section{Potential and participation of forests in the energy matrix}

\begin{abstract}
Mankind is seeking to increase the use of renewable energy sources on the world energetic matrix, aiming on Green House Gas Emissions (GHGE) reduction. Biomass potential for energy generation studies, including forest products and residues, have been conducted worldwide, showing great potential. Besides, wood energy uses contribute to GHGE reduction, and is a locally available energy source at competitive costs in many countries. The proportion of fuelwood on Brazilian energy matrix has decreased over the last four decades, nevertheless consumption has increased during the last ten years. South and Northeast regions are the biggest fuelwood producers in Brazil, Southeast is the main producers of wood charcoal. In order to increase forest biomass potential for energy generation, small and medium farmers forest technology access should be facilitated, and forest plantation area should be increased in order to supply wood biomass rising demand for energy purposes on the near future.
\end{abstract}

\section{Introdução}

Nos últimos três séculos, a humanidade desenvolveu tecnologias que possibilitaram a produção em massa de produtos industriais e de alimentos. As tecnologias para produção industrial foram desenvolvidas a partir do século 18, durante a Revolução Industrial, e o desenvolvimento das tecnologias para produção de alimentos, na Revolução Verde, ocorrida nas décadas de 60 e 70 do século 20. Entretanto, o aumento de 
produção decorrente do uso dessas tecnologias também gerou externalidades negativas, entre elas o aumento das emissões de gases de efeito estufa (GEE) para a atmosfera.

A concentração de dióxido de carbono na atmosfera passou de aproximadamente $280 \mathrm{ppm}$ nos períodos préindustriais (Mudança..., 2000) para 393,18 ppm em abril de 2011 (Tans, 2011), podendo chegar a valores entre 490 ppm e 1.260 ppm no ano de 2100 (Climate..., 2002). Caso esse quadro não seja modificado, a temperatura média da Terra pode aumentar entre $1,4^{\circ} \mathrm{C}$ e $5,8^{\circ} \mathrm{C}$ até 2100, acarretando uma elevação média nos níveis dos oceanos de $9 \mathrm{~cm}$ a $88 \mathrm{~cm}$ nesse mesmo período, além do aumento da precipitação global e intensificação da ocorrência e severidade de eventos climáticos extremos, como furações, enchentes e secas ao redor do planeta (Climate..., 2002).

A substituição de combustíveis fósseis por fontes alternativas de energia tem se apresentado como uma forma promissora de reduzir as emissões de GEE's oriundas de atividades antrópicas. Outra maneira de reduzir a concentração de GEE na atmosfera é o sequestro e armazenamento de carbono na biomassa florestal, por meio da recomposição e plantio de florestas. Entre as fontes renováveis de energia estão a biomassa, nas formas sólida e líquida, os biogases, a energia hidroelétrica e a eólica. Considera-se como biomassa qualquer material vegetal utilizado diretamente como combustível ou convertido em combustível, eletricidade ou calor (International Energy Agency, 2010).

Dentre as fontes de biomassa utilizadas, a madeira se destaca pelo seu potencial de uso na sua forma in natura (lenha), até em produtos processados na forma sólida (carvão vegetal) ou líquida (óleos condenados da pirólise), ou no aproveitamento de resíduos da atividade florestal (restos de podas, galhos) ou industrial (constaneiras, resíduos de serrarias e laminadoras, briquetes), sendo uma fonte de energia renovável acessível e largamente utilizada ao redor do mundo, principalmente em países em desenvolvimento. A madeira para energia também tem, pouco a pouco, se inserido em novos mercados nos países desenvolvidos por ser uma fonte de energia limpa (Trossero, 2002). Outra vantagem do uso da madeira como fonte energética é a possibilidade de sua exploração ou plantio na maioria dos países, a qual, diferente dos combustíveis fósseis, pode ser produzida e disponibilizada nacionalmente, reduzindo a dependência externa.
A biomassa de origem florestal utilizada para energia contribui duplamente para a redução da concentração de GEE: no momento do seu crescimento, devido à absorção e armazenamento de carbono pela fotossíntese; e pela redução da emissão de carbono na sua substituição por combustíveis fósseis. Entretanto, o benefício social e ambiental para a redução das emissões de $\mathrm{CO}_{2}$ é superior na substituição de combustíveis fósseis do que a absorção e armazenamento de carbono pelas florestas (Hall, 1997).

O objetivo deste trabalho foi realizar uma revisão sobre o potencial do uso da biomassa de origem florestal para geração de energia no mundo e no Brasil, evidenciando potencialidades e dificuldades no seu uso para a matriz energética nacional.

\section{As florestas mundiais e a sua contribuição para a matriz energética}

As florestas sempre estiveram presentes na vida do homem ao longo da história da humanidade, tanto com o fornecimento de produtos como de serviços ambientais. Com o passar do tempo e a evolução da sociedade, das suas necessidades, e dos processos industriais, as florestas foram sendo suprimidas para dar lugar a outras formas de uso do solo, ou manejadas de modo a ofertar os seus produtos, mantendo, em certa medida, a sua capacidade de ofertar serviços ambientais.

Segundo os dados da Organização das Nações Unidas para Alimentação e Agricultura (FAO, 2011), a distribuição média mundial do uso do solo, no ano de 2008 , foi de $36,28 \%$ ( 4,88 bilhões de ha) da cobertura do solo sendo utilizada para fins agrícolas, 30,05\% ( 4,04 bilhões de ha) cobertos com florestas, e 30,37\% ( 4,09 bilhões de ha) com outros usos do solo. Com a expansão das atividades antrópicas pelo globo, a média histórica de cobertura do solo mundial com florestas vem diminuindo nas últimas duas décadas, passando de $31 \%$ em 1990 para 30,05\% em 2008.

O Brasil é o segundo maior país com cobertura florestal absoluta do mundo, com aproximadamente 524 milhões de hectares de florestas, que cobrem $61,53 \%$ do território nacional, atrás apenas da Rússia, com 809 milhões de hectares (47,31\%). Os outros três países que completam os cinco principais com maior cobertura florestal em termos absolutos são: Canadá (310 milhões de ha - 31,06\%), Estados Unidos da América (303 milhões de ha - 30,85\%) e China (201 milhões de ha $-20,97 \%)$ (FAO, 2011). 
A produção mundial de madeira bruta, entre 1989 e 2009, foi superior a 130 bilhões de $\mathrm{m}^{3}$, sendo mais da metade destinada para biomassa (energia) (Figura 1). A indústria de serraria e laminação ocupou a segunda posição, sendo que juntamente com a biomassa, representou quase $90 \%$ da destinação da madeira globalmente produzida. Os demais 11\% distribuem-se entre as indústrias de celulose e outras indústrias. Ainda de acordo com a Figura 1, a participação da madeira de não coníferas na produção total de madeira para biomassa foi de quase $90 \%$, evidenciando a quase totalidade do uso de plantas angiospermas para a produção mundial de energia oriunda de madeira bruta (FAO, 2011).

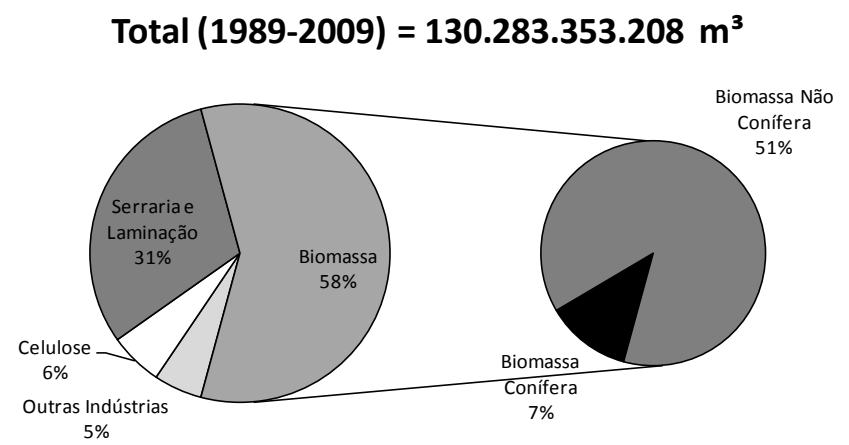

Figura 1. Finalidade da madeira bruta produzida no mundo entre 1989 e 2009. Dados obtidos em FAO (2011).

O último relatório da Agência Internacional de Energia (International Energy Agency, 2010) informa que o consumo de energia mundial vem aumentando com o passar dos anos, passando de 6,11 bilhões de toneladas equivalentes de petróleo $\left(\right.$ Gtep $\left.^{1}\right)$ em 1973, para 12,27 Gtep em 2008, e a expectativa é de que este consumo atinja 16,79 Gtep em 2030, caso seja mantido o processo de desenvolvimento atual, ou possa atingir valores de 14,39 Gtep em 2030 caso os países cheguem a um acordo a respeito da política climática pós 2012 para estabilizar as emissões de GEE em 450 ppm de $\mathrm{CO}_{2}$ equilavente.

A maior parte da energia mundialmente consumida no ano de 2008 foi oriunda de fontes não renováveis, tais como combustíveis líquidos ${ }^{2}(33,2 \%)$, gás natural (21,1\%), carvão mineral (27\%) e energia nuclear $(5,8 \%)$; apenas $12,9 \%$ da energia consumida no mundo em 2008 teve origem em fontes renováveis. A previsão para o ano de 2030 é de que a participação das fontes renováveis aumente para $14,2 \%$ na matriz energética mundial caso o processo de desenvolvimento atual se mantenha, ou 21\%, caso o acordo mundial para estabilização das emissões de GEE em 450 ppm de $\mathrm{CO}_{2}$ equivalente seja ratificado (International Energy Agency, 2010). Atualmente, as fontes renováveis de energia são consideradas como a solução para o problema energético da Europa (Viana et al., 2010).

No relatório sobre mitigação das mudanças climáticas, o Grupo de Trabalho III do Painel Intergovernamental de Mudanças Climáticas (Metz et al., 2007) apresentou um fluxo mundial da energia oriunda de biomassa em 2004 e as suas rotas de conversão termo e bioquímicas para produção de calor, eletricidade e biocombustíveis. Pressupondo-se que este fluxo de conversão permaneceu inalterado em 2008, podemos estimar a participação da lenha e do carvão vegetal na produção dos 12,27 Gtep consumidos na matriz energética mundial em 2008 (Figura 2).

Segundo a FAO (2011), os cinco principais países produtores de madeira para energia entre os anos de 1989 e 2009 foram: Índia (6,08 bilhões de $\left.\mathrm{m}^{3}\right)$, China (4,95 bilhões de $\left.\mathrm{m}^{3}\right)$, Brasil (2,75 bilhões de $\left.\mathrm{m}^{3}\right)$, Indonésia (1,93 bilhões de $\left.\mathrm{m}^{3}\right)$ e Etiópia (1,51 bilhões de $\left.\mathrm{m}^{3}\right)$; sendo responsáveis por $45,14 \%$ da produção mundial (Figura 3).

Todos os principais produtores mundiais de madeira para energia são países em desenvolvimento, e particularmente a Etiópia, o Brasil e a Índia vêm aumentando a produção e o uso de madeira para energia ao longo destas duas décadas, com uma taxa média anual de crescimento de $1,64 \%, 0,87 \%$ e $0,59 \%$, respectivamente. Em caminho oposto, a China e a Indonésia vêm apresentando um decréscimo médio anual de 2,06\% e 3,51\%, respectivamente (Figura 3). Em 2009, o Brasil produziu e consumiu cerca de 142 milhões de $\mathrm{m}^{3}$ de madeira para energia (FAO, 2011).
${ }^{1}$ Um bilhão de toneladas equivalentes de petróleo (Gtep) equivale a 4,1868 x $10^{7}$ Tera Joule ( $\left.\mathrm{TJ}=10^{12} \mathrm{Joule}\right)$ (International Energy Agency, 2005).
${ }^{2}$ Combustíveis líquidos incluem petróleo bruto e condensado, líquidos de gás natural, ganhos de refinarias, biocombustíveis, entre outros. 


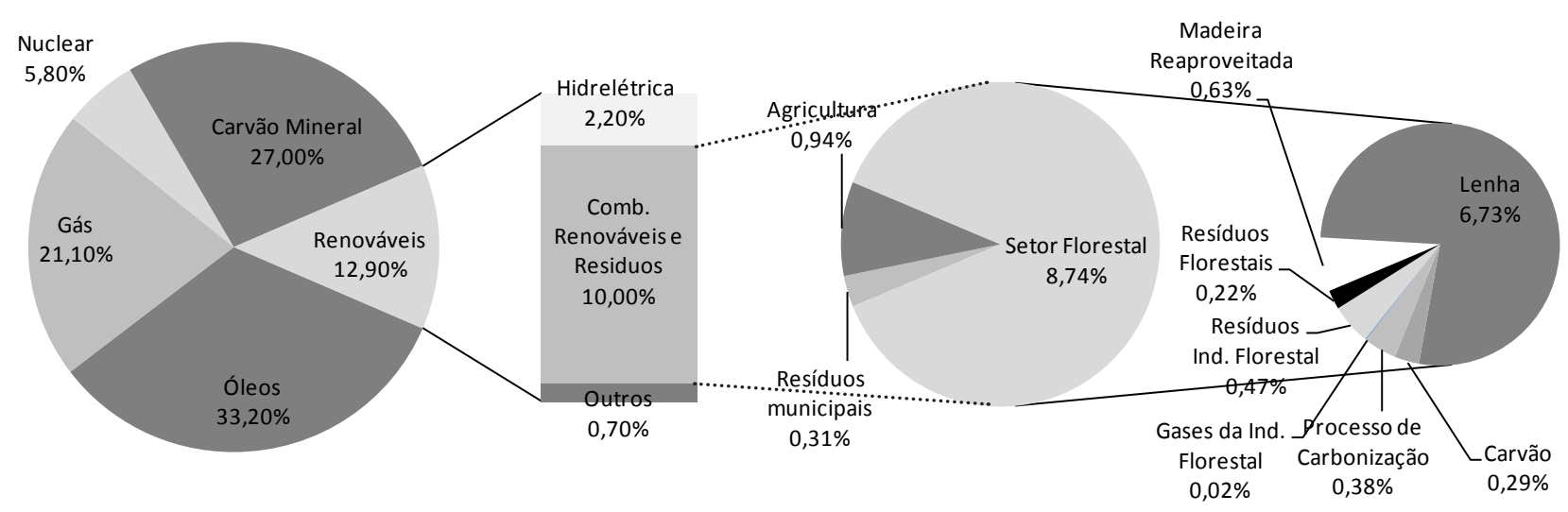

Figura 2. Estimativa da contribuição das fontes de energia para a matriz energética mundial em 2008. Dados obtidos em Metz et al. (2007) e International Energy Agency (2010).

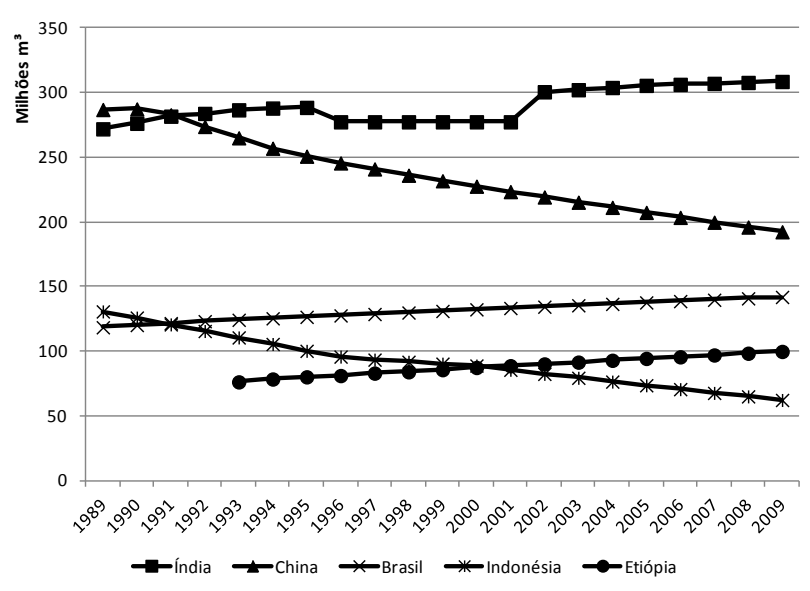

Figura 3. Evolução da produção de madeira para energia pelos cinco maiores produtores mundiais, entre os anos de 1989 e 2009. Dados obtidos em da FAO (2011).

A madeira ainda é largamente utilizada em termos mundiais como fonte de energia e calor, sendo poucas as alternativas que foram desenvolvidas para substituir a madeira nessas funções e que sejam economicamente viáveis (Bunain \& Batalha, 2007). Além disso, proporciona uma fonte de energia com emissão zero de carbono, renovável, capaz de reduzir a demanda externa por combustíveis fósseis, contribuindo para a melhora das contas externas nacionais (reduzindo importações), aumenta o nível de segurança energética nacional por ser uma fonte interna e proporciona maior equidade e justiça social por ser uma das fontes com maior taxa de geração de empregos por unidade monetária investida (Brito, 2007).
Além destas vantagens, é uma fonte de energia acessível a uma grande gama da população, por não necessitar de um massivo aporte de capital para a sua produção, processamento e distribuição, como é necessário para a exploração de outras fontes energéticas (petróleo, gás natural, carvão mineral, hidrelétricas). Esta característica possibilita a participação de um grande número de pequenos produtores e consumidores no mercado de madeira para energia (Brito, 2007), reduzindo a necessidade de intervenção governamental, principalmente no que se refere a investimentos públicos e controle de preços e tarifas.

Estudos sobre o potencial do uso de biomassa, tanto de origem florestal como de outras origens, tem sido realizados para diversos países ou regiões do globo. Na América do Norte, Paré et al. (2011) estudaram o potencial da biomassa florestal para a oferta de energia no Canadá, e chegaram à conclusão de que a principal fonte de biomassa florestal disponível para geração de energia seriam os resíduos primários da exploração florestal, os quais apresentam forte potencial para a geração de energia mas não seriam suficientes para atender uma parcela significativa da demanda energética do país. Gonzalez et al. (2011) realizaram uma análise financeira da utilização de eucalipto para a geração de energia no sul dos Estados Unidos da América, levando em consideração os custos de manejo, remuneração da terra e do capital, além do frete para uma distância de 48,3 quilômetros. Os autores chegaram à conclusão que, para as condições avaliadas, o eucalipto apresenta um custo competitivo para ser utilizado como matéria-prima para geração de energia nos Estados Unidos. 
Viana et al. (2010) analisaram o potencial de geração de energia a partir dos resíduos primários do manejo florestal em Portugal, frente aos planos governamentais de aumentar a participação da energia renovável na sua matriz energética. A opção pela biomassa florestal para geração de energia originou-se da possibilidade do aumento de empregos na produção florestal, do potencial de cogeração de calor e energia de maneira competitiva entre as fontes renováveis, da versatilidade e da disponibilidade dessa fonte de energia pelo país, dos custos relativamente baixos, da redução da dependência externa, da promoção das economias regionais e da criação de uma fonte de renda alternativa para os agricultores do país. Os autores concluíram que a oferta de biomassa oriunda dos resíduos primários das plantações florestais não será suficiente para atender a demanda energética em algumas regiões do país, mas que este quadro se reverte se a tecnologia de cogeração de energia e calor for adotada como meio de conversão de madeira para energia.

$\mathrm{Na}$ Alemanha, de todas as formas de geração de energia a partir de biomassa avaliadas por König (2011), a geração de calor ou processo conjunto de geração de calor e energia a partir da biomassa sólida como madeira ou palha apresentaram os custos mais atrativos para se atingir os níveis desejados de redução de GEE. Ainda na Europa, Montenegro obtém 6\% da sua energia com a queima da madeira, podendo mais do que dobrar o seu uso em um futuro próximo caso resíduos oriundos da indústria florestal forem utilizados para geração de energia, principalmente se os resíduos forem compactados em briquetes (Danon et al., 2010). $O$ potencial da biomassa de origem florestal também mereceu destaque na China, representando 32\% do potencial de uso da biomassa para geração de energia, avaliado em 887 milhões de tep (Yanli et al., 2010).

Os estudos anteriores reforçam as conclusões de Hall (1997), de que há um forte potencial para a modernização da geração de energia a partir de biomassa, gerando eletricidade e combustíveis gasosos e líquidos, aumentando a sua participação na matriz energética mundial além daquela já obtida pelas formas tradicionais de geração de energia a partir de biomassa.

A estrutura de coleta e uso da madeira para energia (Trossero, 2002) e os custos envolvidos na complexa logística de colheita ou coleta da lenha até o seu destino final (Iakovou, 2010) constituem dois fatores de extrema importância a serem considerados em estudos de viabilidade do potencial de uso da madeira para geração de energia. Tais considerações evitarão erros cometidos como em alguns trabalhos realizados na década de 1980, que sinalizaram uma previsão equivocada de falta de lenha nos países em desenvolvimento devido à superexploração das florestas. Tal equívoco se sucedeu em decorrência da crença de que o uso da lenha e do carvão vegetal era causa irreparável da supressão da vegetação nativa nas zonas urbanas e periféricas, por falta de conhecimento acerca do processo de coleta/ colheita de lenha pelas populações que dela faziam uso (Trossero, 2002).

\section{As florestas no Brasil e a sua contribuição para matriz energética nacional}

\section{Distribuição da área florestal no Brasil}

O Brasil é o terceiro maior país com cobertura florestal do mundo (FAO, 2011), mas esta cobertura tem diminuído ao longo das duas últimas décadas, devido à supressão de áreas florestais para dar lugar a outros usos do solo (Tabela 1). O Brasil perdeu quase 51 milhões de hectares de florestas entre 1990 e 2008, as quais foram transformadas em aproximadamente 23 milhões de hectares de área agrícola e 28 milhões de hectares de área para outros usos (Tabela 1).

Tabela 1. Proporção do uso do solo no Brasil em 1990 e 2008.

\begin{tabular}{lrr}
\hline $\begin{array}{c}\text { Usos da Terra } \\
\text { (mil ha) }\end{array}$ & $\mathbf{1 9 9 0}$ & \multicolumn{1}{c}{$\mathbf{2 0 0 8}$} \\
\hline Agrícola & $241.608(28,37 \%)$ & $264.500(31,06 \%)$ \\
Florestas & $574.839(67,51 \%)$ & $523.911(61,53 \%)$ \\
Água & $5.546(00,65 \%)$ & $5.546(00,65 \%)$ \\
Outros usos & $29.495(03,46 \%)$ & $57.531(06,76 \%)$ \\
Total & $851.488(100,00 \%)$ & $851.488(100,00 \%)$ \\
\hline
\end{tabular}

Dados obtidos em FAO (2011).

Atualmente, a quase totalidade da cobertura florestal brasileira advém de florestas nativas, uma vez que as florestas plantadas ocupam 6.973.083 hectares (Anuário..., 2011), o que representa apenas 1,33\% da cobertura florestal nacional, e $0,82 \%$ do território nacional. As espécies mais plantadas no país pertencem ao gênero Eucalyptus ssp., ocupando 68,2\% da área ocupada pelos plantios nacionais. O segundo gênero mais representativo em termos de área plantada no Brasil é o Pinus ssp., com 25,2\%. Os demais 6,6\% das áreas plantadas são ocupadas com outras espécies florestais 
(acácia, seringueira, paricá, teca, pinheiro-do-paraná, pópulus, entre outras).

O estado brasileiro com maior área absoluta de florestas plantadas em 2010 foi Minas Gerais, seguido por São Paulo, Paraná e Bahia, que juntos abrigam $65,26 \%$ dos plantios florestais nacionais. A Tabela 2 permite observar a evolução da área plantada nos estados brasileiros, bem como a taxa média de crescimento da área plantada de cada um entre 2004 e 2010.

Tabela 2. Evolução da área com florestas plantadas por Unidades da Federação (UF).

\begin{tabular}{|c|c|c|c|c|c|c|c|c|}
\hline UF & 2004 & 2005 & 2006 & 2007 & 2008 & 2009 & 2010 & Taxa (\%) \\
\hline MG & 1.190 .048 & 1.269 .174 & 1.327 .429 & 1.361 .607 & 1.423 .210 & 1.440 .000 & 1.536 .310 & 4,3 \\
\hline SP & 888.002 & 946.542 & 1.130 .332 & 1.121 .529 & 1.173 .560 & 1.197 .330 & 1.206 .818 & 5,2 \\
\hline PR & 774.518 & 792.768 & 808.361 & 824.648 & 857.320 & 853.710 & 847.931 & 1,5 \\
\hline BA & 533.665 & 582.132 & 594.992 & 591.348 & 622.700 & 659.480 & 658.034 & 3,6 \\
\hline $\mathrm{SC}$ & 573.398 & 588.245 & 601.333 & 622.045 & 628.660 & 650.990 & 647.991 & 2,1 \\
\hline $\mathrm{RS}$ & 322.455 & 364.770 & 365.623 & 404.623 & 450.480 & 443.190 & 441.997 & 5,4 \\
\hline MS & 126.717 & 152.341 & 147.819 & 228.384 & 284.050 & 307.760 & 392.042 & 20,7 \\
\hline ES & 183.767 & 208.933 & 212.208 & 212.912 & 214.400 & 208.510 & 207.431 & 2,0 \\
\hline PA & 100.793 & 106.182 & 115.955 & 126.387 & 136.300 & 139.720 & 148.656 & 6,7 \\
\hline MA & 57.852 & 60.745 & 93.285 & 106.802 & 111.120 & 137.360 & 151.403 & 17,4 \\
\hline GO & 56.806 & 60.872 & 64.046 & 65.107 & 72.080 & 73.140 & 70.679 & 3,7 \\
\hline $\mathrm{AP}$ & 83.742 & 87.928 & 78.963 & 67.874 & 64.930 & 63.690 & 49.384 & $-8,4$ \\
\hline MT & 42.459 & 42.460 & 46.153 & 57.158 & 58.590 & 61.540 & 61.950 & 6,5 \\
\hline TO & - & 2.124 & 13.901 & 22.355 & 32.770 & 45.160 & 48.392 & 86,9 \\
\hline PI & - & - & - & - & - & - & 37.025 & - \\
\hline Outros & 29.289 & 28.988 & 31.680 & 31.588 & 27.580 & 28.870 & 4.650 & $-*$ \\
\hline Total & 4.963 .511 & 5.294 .204 & 5.632 .080 & 5.844 .367 & 6.157 .750 & 6.310 .450 & 6.510 .693 & 4,6 \\
\hline
\end{tabular}

A taxa média de crescimento da área florestal não foi calculada devido à remoção do Piauí da categoria Outros no ano de 2010. Fonte: Anuários Estatísticos da ABRAF (Anuário..., 2008, 2011).

Em termos de região, o Sudeste concentrou em 2010 a maior parte dos plantios florestais $(45,4 \%)$, seguido pela região Sul (29,8\%), Nordeste (13\%), Centro-Oeste $(8,1 \%)$ e Norte $(3,8 \%)$, o que evidencia uma maior tradição da metade sul do país no plantio de florestas, com mais de três quartos da área plantada.

\section{Distribuição da produção florestal no Brasil}

A produção florestal brasileira, de acordo com os dados do Instituto Brasileiro de Geografia e Estatística (IBGE, 2011), divide-se em dois grandes grupos: os produtos oriundos da extração vegetal, e os oriundos da silvicultura.

A evolução da quantidade produzida de lenha, tanto na extração vegetal como na silvicultura, no país entre 1990 e 2009 é apresentada na Figura 4. Percebe-se que os produtos gerados a partir da silvicultura estão em ascensão, enquanto que os produtos advindos da extração vegetal estão em queda, principalmente devido ao aumento da fiscalização do desmatamento e da exploração das florestas nativas sem um plano de manejo. $\mathrm{O}$ comportamento da produção de carvão vegetal no país apresenta oscilações entre crescimento e diminuição da produção ao longo do período analisado. A tendência mais clara no comportamento da produção de carvão vegetal no país é uma maior quantidade produzida de florestas plantadas, em relação ao extraído de florestas nativas (Figura 5).

Em geral, as indústrias preferem utilizar o carvão vegetal de florestas plantadas (silvicultura) do que de florestas nativas, entretanto, a oferta de madeira de florestas plantadas é relativamente pouco flexível no curto prazo, e espera-se que a madeira para energia oriunda da extração vegetal e da silvicultura sejam produtos substitutos, de modo que um aumento da demanda por madeira de silvicultura para outros fins poderá reduzir a quantidade ofertada dessa madeira para energia. Isto provocaria um aumento do seu preço, elevando a demanda de madeira de extração vegetal para 
abastecer os consumidores de madeira para energia, o que poderia resultar em aumento do desflorestamento de áreas nativas.

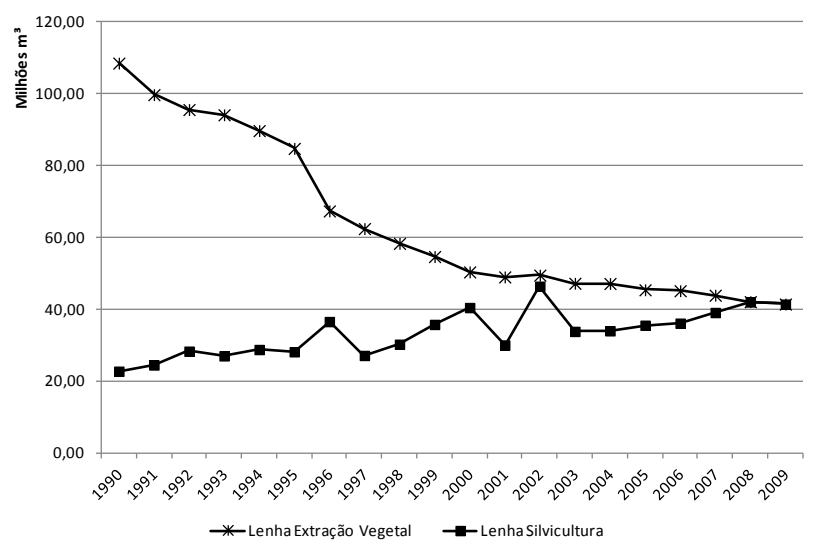

Figura 4. Evolução da produção de lenha no Brasil, entre os anos de 1990 e 2009. Dados obtidos em do IBGE (2011).

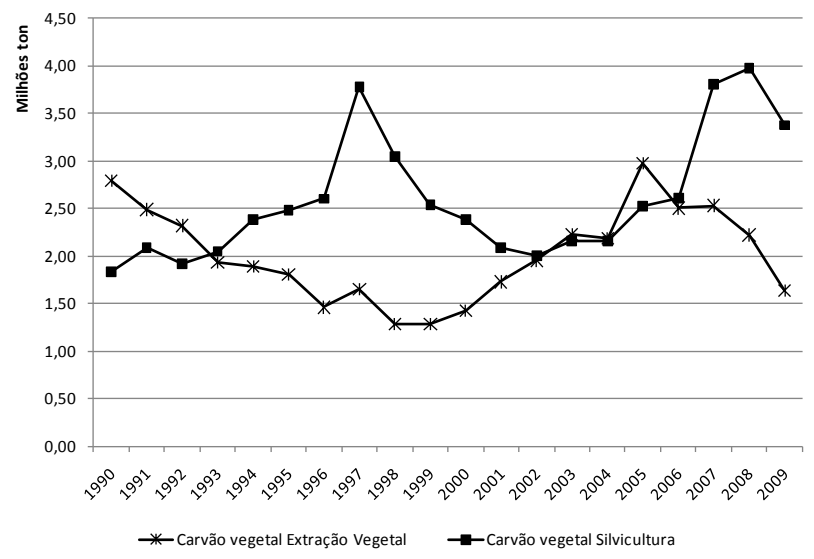

Figura 5. Evolução da produção de carvão vegetal no Brasil, entre os anos de 1990 e 2009. Dados obtidos em IBGE (2011).

A Tabela 3 apresenta a soma das produções de madeira em tora, lenha e carvão, nos períodos entre 1990 e 2009, e dos últimos três anos, para cada região brasileira, por fonte de produção. A região Sudeste apresenta a maior produção de carvão vegetal do país, fato já esperado uma vez que Minas Gerais consome cerca de $60 \%$ do carvão vegetal produzido no país e apresenta uma área plantada de 1.219.000 hectares de florestas para fins energéticos (Calais, 2009).

Considerando o período entre1990 e 2009, a segunda região produtora de carvão vegetal foi o CentroOeste, seguida de perto pelo Nordeste. Entretanto, se considerarmos a produção dos últimos três anos, o Nordeste é o segundo maior produtor nacional de carvão vegetal, com quase o dobro da produção do Centro-Oeste. Isto pode ser explicado pela instalação de um polo guseiro no Estado do Maranhão, responsável por $67,78 \%$ da produção de carvão vegetal da região nordeste neste período.

Ao analisarmos o período mais recente (2007 a 2009), uma diferença significativa se observa no comportamento do Nordeste e do Sudeste com relação à produção de carvão vegetal; o segundo obteve quase $90 \%$ do seu carvão a partir de florestas plantadas, enquanto que o Nordeste obteve $63 \%$ do seu carvão a partir de florestas nativas (extração vegetal).

A produção de lenha, utilizada como uma fonte primária de energia oriunda da madeira, também apresentou alternância entre as regiões de maior produção no país, ao se considerar o período entre 1990 e 2009. O Nordeste foi o maior produtor de lenha do país, mas se observarmos apenas os últimos três anos, a região ocupou a segunda posição, atrás da região Sul. Entretanto, mais de 95\% da lenha produzida no Nordeste veio da extração vegetal, enquanto no Sul este percentual foi de apenas $17 \%$. Isto traz a tona uma preocupação principalmente com a região Nordeste do país, cuja vegetação nativa apresenta baixa produtividade de madeira e apenas $0,3 \%$ da vegetação nativa estava sob regime de manejo florestal sustentado (Associação Plantas do Nordeste, 2011). Isto pode ter sérias consequências sociais no futuro, tanto na geração de emprego das atividades industriais que dependem da lenha como fonte de energia como para o consumo doméstico. Estima-se que $60 \%$ das famílias no nordeste utilizam a lenha para cocção de alimentos (Santos \& Gomes, 2009). 
Tabela 3. Distribuição da produção de carvão vegetal e lenha nas regiões do Brasil.

\begin{tabular}{|c|c|c|c|c|c|}
\hline \multirow{2}{*}{ Região } & \multirow{2}{*}{$\begin{array}{l}\text { Sistema de } \\
\text { produção }\end{array}$} & \multicolumn{2}{|c|}{ Período 1990-2009 } & \multicolumn{2}{|c|}{ Período 2007-2009 } \\
\hline & & Carvão vegetal $^{1}$ & Lenha $^{2}$ & Carvão vegetal $^{1}$ & Lenha $^{2}$ \\
\hline \multirow{2}{*}{ Norte (NO) } & Extração Vegetal & 5.445 .995 & 163.913 .674 & 438.621 & 21.975 .279 \\
\hline & Silvicultura & 6.187 & 1.836 .861 & 12 & 168.900 \\
\hline NO Total & & 5.452 .182 & 165.750 .535 & 438.633 & 22.144.179 \\
\hline \multirow{2}{*}{ Nordeste (NE) } & Extração Vegetal & 9.943 .711 & 665.411 .789 & 2.550 .792 & 70.169 .714 \\
\hline & Silvicultura & 4.144 .508 & 44.602 .235 & 1.465 .162 & 3.237 .496 \\
\hline NE Total & & 14.088.219 & 710.014.024 & 4.015.954 & 73.407.210 \\
\hline \multirow{2}{*}{$\begin{array}{l}\text { Centro Oeste } \\
(\mathrm{CO})\end{array}$} & Extração Vegetal & 9.510 .517 & 115.637 .758 & 1.890 .620 & 11.379 .060 \\
\hline & Silvicultura & 5.919 .841 & 28.536 .512 & 244.926 & 4.863 .070 \\
\hline CO Total & & 15.430 .358 & 144.174.270 & 2.135.546 & 16.242 .130 \\
\hline \multirow{2}{*}{ Sudeste (SE) } & Extração Vegetal & 13.231 .687 & 129.433 .303 & 1.111 .779 & 7.534 .812 \\
\hline & Silvicultura & 40.335 .562 & 240.883 .778 & 9.171 .178 & 35.341 .948 \\
\hline SE Total & & 53.567.249 & 370.317 .081 & 10.282 .957 & 42.876 .760 \\
\hline \multirow{2}{*}{ Sul (S) } & Extração Vegetal & 2.173 .181 & 202.431 .386 & 400.379 & 16.408 .395 \\
\hline & Silvicultura & 1.406 .815 & 352.323 .922 & 278.653 & 78.926 .559 \\
\hline S Total & & 3.579 .996 & 554.755 .308 & 679.032 & 95.334.954 \\
\hline
\end{tabular}

${ }^{1}$ toneladas (ton), ${ }^{2}$ metros cúbicos $\left(\mathrm{m}^{3}\right)$.

Problemas de escassez de madeira também são esperados no setor siderúrgico nacional. Pouco mais da metade da demanda de madeira para energia deste setor é atualmente atendido por madeiras de reflorestamento. E de acordo com a previsão da expansão da área de florestas plantadas pelo setor, o montante não será suficiente para atender as demandas dos principais pólos siderúrgicos nacionais (Minas Gerais, Carajás, Espírito Santo e Mato Grosso do Sul), estimando-se um déficit de 600 mil hectares de plantios florestais destinados a florestas para energia (Calais, 2009).

\section{A energia florestal na matriz energética brasileira}

A produção energética de fontes primárias no Brasil aumentou 486\% entre os anos de 1970 (49,6 Mtep) e 2009 (241 Mtep) (Brasil, 2011). Entretanto, ao longo desse período, a participação das fontes não renováveis na produção primária aumentou de $21,2 \%$ para 53,3\% (Figura 6). A participação da lenha na produção energética primária no Brasil acompanhou a tendência das outras fontes renováveis, caindo de $64 \%$ em 1970 para 10,2\% em 2009. Entretanto, a produção absoluta de energia primária a partir da lenha tem aumentado a partir de 1998, seguindo uma tendência de alta até 2008 e voltando a cair em 2009 (Brasil, 2011).

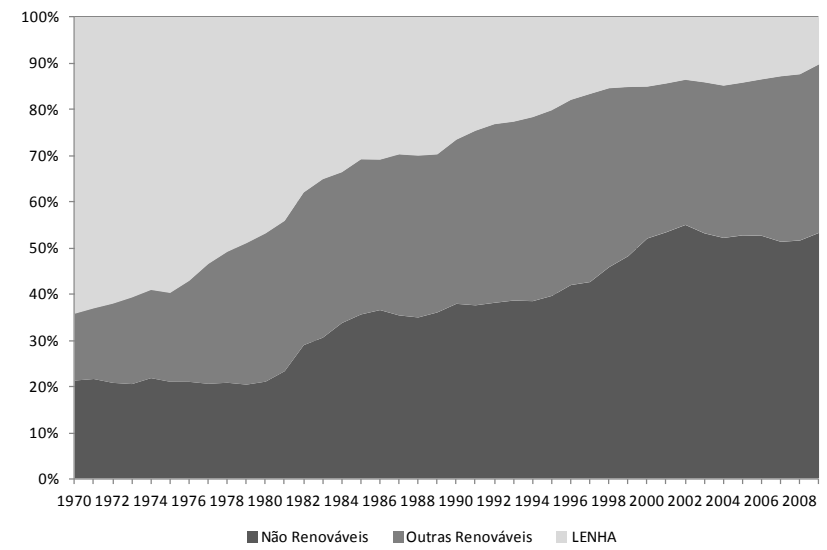

Figura 6. Evolução da participação das energias renováveis e não-renováveis na produção primária de energia no Brasil, entre os anos de 1970 e 2009. Dados obtidos em Brasil (2011).

Não há exportação ou importação de lenha no Brasil, de modo que a produção interna é igual ao seu consumo. Os principais setores consumidores nos três últimos anos foram o residencial, com $28 \%$ da energia total da lenha ofertada no país, seguido pelo setor industrial, com $23,2 \%$. Os demais setores consumidores de lenha foram o agropecuário $(8,9 \%)$ e o comercial $(0,3 \%)$. 
Dentre os setores industriais da economia, dois setores apresentam-se como os principais consumidores de lenha, a indústria de cerâmicas com 6,09 milhões de tep $(31,8 \%)$ e a de alimentos e bebidas com 5,92 milhões de tep $(30,9 \%)$. A indústria de papel e celulose marca presença como o terceiro maior setor consumidor de energia de lenha, com 4,12 milhões de tep $(21,5 \%)$, os demais setores consomem $15,9 \%$ da energia produzida. Vale salientar que o consumo de lenha pelo setor de ferro gusa não ocorre na matriz energética nacional, sendo a sua relação energética com o setor florestal concretizada a partir do consumo de energia oriunda de carvão vegetal (Brasil, 2011).

As carvoarias consumiram aproximadamente 32 milhões de tep de lenha para produção de carvão vegetal entre 2007 e 2009, gerando 16,92 milhões de tep de energia sob a forma de carvão vegetal, que adicionados 10,45 mil tep oriundos de importação, e subtraídos 24 mil tep (utilizados nas centrais elétricas autoprodutoras) e 472,5 mil tep perdidos na distribuição e armazenagem, resultaram em 16,426 milhões de tep para consumo final nos diferentes setores da sociedade brasileira. A eficiência média da conversão energética de lenha para carvão vegetal foi de 52,9\% (32 milhões de tep de lenha, gerando quase 17 milhões de tep de carvão vegetal). A Figura 7 apresenta a distribuição do consumo final da energia de carvão vegetal no Brasil entre os anos de 2007 e 2009. É possível perceber que quase três quartos da energia consumida no país a partir de carvão vegetal foi utilizada pelo setor de ferro gusa e aço, o que o torna um importante ator no mercado de madeiras energéticas no país.

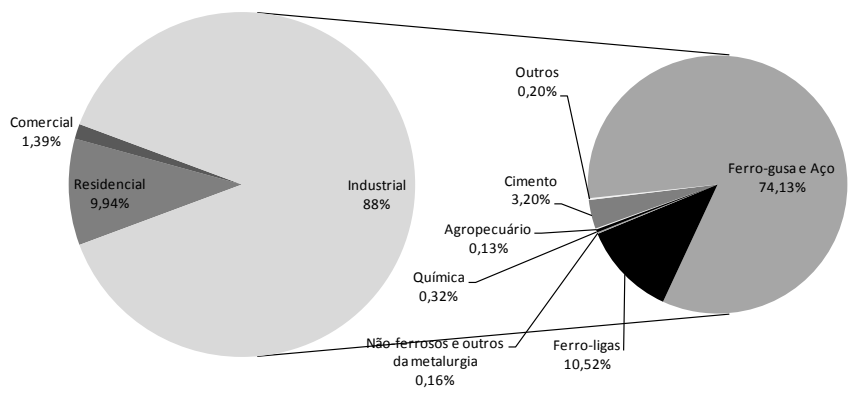

Figura 7. Participação dos setores no consumo final de carvão vegetal no Brasil entre os anos de 2007 e 2009. Fonte: Elaborado pelo autor a partir de dados de Brasil (2011).
Entretanto, o acesso à tecnologia de produção florestal e à representação setorial tem se restringido aos grandes produtores, e as políticas públicas de incentivo à cadeia produtiva de madeira para energia permanecem tímidas (Simioni \& Hoeflich, 2007), não se acreditando em novos incentivos para o plantio de florestas (Buanain \& Batalha, 2007). Muitos produtores pequenos possuem plantios de baixa produtividade, que aliados aos métodos pouco eficientes utilizados na carbonização da madeira reduzem o potencial de geração de energia de parte dos plantios atuais (Fontes, 2005). O mercado vive atualmente uma realidade de escassez de madeira oriunda de florestas plantadas para energia, onde os plantios atuais não serão suficientes para atender a demanda no curto e médio prazos (Fontes, 2005; Calais, 2009).

\section{Conclusão}

Com a crescente demanda por fontes renováveis de energia, estudos a respeito do potencial de geração de energia a partir da biomassa florestal têm sido realizados no Brasil e no mundo, relatando o potencial da biomassa, inclusive a madeira, para geração de energia limpa. Entretanto, para aumentar a eficiência de conversão de madeira em energia é necessária a adoção de tecnologias mais apropriadas para combustão, carbonização e geração de energia elétrica. Além disso, é de fundamental importância levar em consideração os custos de coleta e a logística do aproveitamento da biomassa florestal para avaliar o seu verdadeiro potencial para geração de calor e cogeração de energia e calor.

O Brasil é um grande produtor e consumidor mundial de lenha e madeira para energia, sendo as regiões Sul e Nordeste as duas maiores produtoras de lenha do país, diferindo principalmente na origem da lenha produzida. Enquanto o Sul produz prioritariamente florestas plantadas, o Nordeste tira a maior parte da sua produção do extrativismo vegetal (florestas nativas).

A lenha tem perdido participação na matriz energética nacional, contribuindo com $10 \%$ da energia gerada a partir de fontes primárias em 2009, mas o valor absoluto da energia gerada a partir da lenha têm aumentado desde 1998.

Para que o Brasil possa aumentar a participação da lenha e produtos da madeira na sua matriz energética, são necessárias melhorias no acesso a tecnologia florestal para pequenos e médios produtores, tanto de silvicultura como de conversão da madeira em energia, aumentando o potencial de geração de energia de plantios futuros. 


\section{Referências}

ANUÁRIO estatístico da ABRAF 2011: ano base 2010. Brasília, DF: ABRAF, 2011. 130 p. Disponível em: <http://www.abraflor. org.br/estatisticas/ABRAF11/ABRAF11-BR.pdf>. Acesso em: 22 mai 2011.

ANUÁRIO estatístico da ABRAF 2008: ano base 2007. Brasília, DF: ABRAF, 2008. 87 p. Disponível em: $<$ http://www.abraflor. org.br/estatisticas/ABRAF08-BR.pdf>. Acesso em: 09 fev. 2011.

ASSOCIAÇÃO PLANTAS DO NORDESTE. Centro Nordestino de Informações sobre Plantas. Planos de manejo florestal sustentado na Caatinga. Recife, [2011]. Disponível em: <http:// www.cnip.org.br/planos_manejo.html>. Acesso em: 13 fev. 2011.

BRASIL. Ministério de Minas e Energia. Balanço energético nacional: matrizes consolidadas 1970-2009. Brasília, DF: 2011. Disponível em: $<$ https://ben.epe.gov.br/BENSeriesCompletas. aspx>. Acesso em: 10 fev. 2011.

BRITO, J. O. O uso energético da madeira. Estudos Avançados, v. 21, n. 59, p. 185-193, jan./mar. 2007.

BUAINAIN, A. M.; BATALHA, M. O. Cadeia produtiva de madeira. Brasília, DF: IICA: MAPA/SPA, 2007. 86 p. (Série agronegócios, 6).

CALAIS, D. Florestas energéticas no Brasil: demanda e disponibilidade. [S.1.]: Associação Mineira de Silvicultura, 2009. 23 p. Disponível em: <http://www.silviminas.com.br/Publicacao/ Arquivos/publicacao_585.pdf>. Acesso em: 11 fev. 2011.

CLIMATE chance: information kit. Bonn: UNFCC; Paris, Geneva: UNEP, 2002. 64 p.

DANON, G. J.; ANDJELIC, M. B.; GLAVONJIC, B. D.; KADOVIC, R. B.; FURTULA, M. A. Wood biomass for energy in Montenegro. Thermal Science, v. 14, n. 4, p. 783-798, 2010.

FAO. FAOSTAT: ForesSTAT. Rome, 2011. Disponível em: $<$ http://faostat.fao.org/site/626/default.aspx\#ancor $>$. Acesso em: 05 fev. 2011.

FONTES, A. A. A cadeia produtiva da madeira para energia. Viçosa, MG, 2005. 134 f. Tese (Doutorado em Ciência Florestal) Universidade Federal de Viçosa, Viçosa, MG.

GONZALEZ, R.; TREASURE, T.; WRIGHT, J.; SALONI, D.; PHILLIPS, R.; ABT, R.; JAMEEL, H. Exploring the potential of Eucalyptus for energy production in the Southern United States: financial analisys of delivered biomass. Part I. Biomass \& Bioenergy, v. 35, n. 2, p. 755-766, 2011.

HALL, D. O. Biomass energy in industrialised coutries: a view of the future. Forest Ecology and Management, v. 91, n. 1, p. 17-45, 1997.

IAKOVOU, E.; KARAGIANNIDIS, A.; VLACHOS, D.; TOKA, A.; MALAMAKIS, A. Waste biomass-to-energy supply chain management: a critical synthesis. Waste Management, v. 30, n. 10, p. 1860-1870, 2010.
IBGE. Sistema IBGE de recuperação automática: SIDRA. Rio de Janeiro, 2011. Disponível em: < http://www.sidra.ibge.gov.br/>. Acesso em: 21 fev. 2011.

INTERNATIONAL ENERGY AGENCY. 2010 key world energy statistics. Paris, 2010, 82 p.

INTERNATIONAL ENERGY AGENCY. Energy statistics manual. Paris, 2005, 196 p.

METZ, B.; DAVIDSON, O. R.; BOSCH, P. R.; DAVE, R.; MEYER, L. A. (Eds.). Climate change 2007: mitigation of climate change. Cambridge, UK: Cambridge University Press, 2007. 851 p. Contribution of Working Group III to the Fourth Assessment Report of the Intergovernmental Panel on Climate Change.

KÖNIG, A. Cost efficient utilization of biomass in the German energy system in the context of energy and environmental policies. Energy Policy, v. 39, n. 2, p. 628-636, 2011.

MUDANÇA do clima 1995: a ciência da mudança do clima. Brasília, DF: Ministério da Ciência e Tecnologia, 2000. 56 p. Disponível em: <http://www.mct.gov.br/UserFiles//ipcc.pdf $>$. Acesso em: 15 mar. 2009. Sumário para formuladores de políticas e sumário técnico do relatório do Grupo de Trabalho I.

PARÉ, D.; BERNIER, P.; THIFFAULT, E.; TITUS, B. D. The potential of forest biomass as an energy supply for Canada. The Forestry Chronicle, v. 87, n. 1, p. 71-76, 2011.

SANTOS, S. C. de J.; GOMES, L. J. Consumo e procedência de lenha pelos estabelecimentos comerciais de Aracaju-SE. Revista da Fapese, v. 5, n. 1, p. 155-164, jan./jun. 2009. Disponível em: $<$ http://www.fapese.org.br/revista_fapese/v5n1/artigo12.pdf $>$. Acesso em: 13 fev. 2011.

SIMIONI, F. J.; HOEFLICH, V. A. Análise diagnóstica e prospectiva da cadeia produtiva de energia de biomassa de origem florestal. Colombo: Embrapa Florestas, 2007. 125 p. (Embrapa Florestas. Documentos, 151).

TANS, P. Trends in atmospheric carbon dioxide: Mauna Loa. Boulder, CO: NOAA/ESRL, [2011]. Disponível em: <www.esrl. noaa.gov/gmd/ccgg/trends/>. Acesso em: 17 maio 2011.

TROSSERO, M. A. Dendroenergía: perspectivas de futuro. Unasylva, v. 53, n. 211, p. 3-12, 2002.

VIANA, H.; COHEN, W. B.; LOPES, D.; ARANHA, J. Assessment of forest biomass for use as energy: GIS-based analysis of geographical availability and locations of wood-fired power plants in Portugal. Applied Energy, v. 87, n. 8, p. 25512560, 2010.

YANLI, Y.; PEIDONG, Z.; WENLONG, Z.; YONGSHENG, T.; YONGHONG, Z.; LISHENG, W. Quantitative appraisal and potential analysis for primary biomass resources for energy utilization in China. Renewable and Sustainable Energy

Reviews, v. 14, n. 9, p. 3050-3058, 2010. 